\title{
SMART CITIES AND VALUE OF TIME: AN INTERNATIONAL SYMPOSIUM
}

\author{
SUMMARY OF KEYNOTE SESSIONS
}

Cómo citar: Geurs, K., Robusté, F., La Paix, L., Rangel, T., \& Pritchard, J. (2018). Smart cities and value of time: An International Symposium. Ciencia, Ingenierías y Aplicaciones, 1(1), 71-78. doi:http://dx.doi.org/10.22206/cyap.2018.v1i1.pp71-78

\begin{abstract}
Travel time and activity time have been treated as separate notions, albeit with some assumed interdependencies. But, previous studies show that people accept noticeable higher travel time ratios when travelling by public transport compared with travelling by car. The cost of travel time is reduced as travel time is converted as activity time (towards the productive use). Furthermore, the impact of a high quality journey is an important issue in lifestyle and distribution of activities. The efficiency, safety and productivity of the journey can be expected to impact the value of time. And, the proportion of travel time saved, which can be used for other activities might have positive effects on the quality of life. In recent years some significant ICT-related innovations have been introduced to large shares of society, but research on the current relation between characteristics of ICT-use and its impact on mobility is limited.

Development of smart cities and urban living labs is strongly affected by the ICT use and mobility patterns, as urban living labs co-create new products from collaboration between public, private and civic partnerships. At the same time, in certain self-constrained environments, activity duration has many effects in travel patterns for out-ofhome activities. Use of big data to model travel behaviour might bring important implications for individual mobility. Similarly, traffic safety and management of transport infrastructure are a main concern for government decisions in developing countries.
\end{abstract}

This paper contains a summary of five keynote sessions of the Symposium Smart Cities and Value of Time, that took place in Santo Domingo, Dominican Republic in January 18 and 19 2018. This symposium aimed to contribute to the debate on planning transport system and urban development according to the needs and activities undertaken by citizens of the modern 'on move' society. This summary presents 
five key points of transport research oriented to smart cities and value of time, which can be mentioned as: user's perspective (equity), data collection and infrastructure (traffic safety and network design). These topics are substantially important to estimate accurate travel demand models, and therefore design efficient transport measures.

\section{Implementations of smartphone-based data collection in transport}

Prof. Dr. Karst Geurs, University of Twente, the Netherlands Correo-e: k.t.geurs@utwente.nl

A large scale 3-year smartphone-based panel study, the Dutch Mobile Mobility Panel, recorded departure and arrival times, origins, destinations, modes, and travel purposes were during four weeks period in 2013, 2014 and 2015 using the MoveSmarter app for a representative sample of over 600 respondents, yielding over 125,000 thousand trips. During the monitoring period, respondents also participated in a web-based prompted recall survey and answered additional questions. This enables a comparison between automatic detected and reported trips. A number of studies have been conducted using the data from the panel. Firstly, research has been conducted to examine the accuracy of trip detection. Results showed that most trips were detected with no clear biases in trip length or duration, and transport modes were classified correctly for over $80 \%$ of these trips. In the Dutch Mobile Mobility Panel, trip rates are substantially higher than trip-diary based travel surveys in the Netherlands, in particular for business and leisure trips which are often irregular. Secondly, The Mobile Mobility Panel data have also been used to examine intrapersonal and interpersonal variation in mode choice in the Netherlands and route choice of cyclists. Results show that that intrapersonal mode choice variation is significant in the Netherlands and strongly depends on trip distance. Intrapersonal variation is relatively high for short distance trips (less than $2 \mathrm{~km}$ ) as travelers with the car as a dominant mode also regularly walk and/or bike, especially for non-work trips. Thirdly, route choice of cyclists have been studies. Multinomial logit models have estimated 
and shown that for repeated trips, the shortest route option tends to be chosen more: frequent cyclists, on systematic trips, tend to optimize their trip and to prefer the shortest routes. In the case of leisure trips, people tend to choose a more personalized route, instead of the shortest.

A number of studies have been conducted where smartphones have been used as in instrument for transport demand management in the Twente Region in the Netherlands. In the Smart Enschede project and the European project EMPOWER smart phone apps are used to deliver positive incentives aiming to persuade people to make changes in their transport choices. Smartphone users receive information, feedback on their travel behavior and gamification is used to stimulate users to use environmentally friendly transport modes.

The main conclusion from the set of smartphone studies is that firstly smartphones are efficient and effective data collection tool and provides rich data for studies to study inter-personal and intra-personal variation in route choice, mode choice and destination choice. There is also strong evidence that smartphone-based trip detection can helps to improve the accuracy of travel surveys, reduce underreporting of trips which is a common phenomenon in travel surveys. Secondly, experiments with positive incentives to promote cycling (social rewards, in-kind gifts, money, competition and cooperation) show that positive incentives may encourage non-cyclists to start cycling if distances are short and travel costs are an important consideration in their travel choices. But positive incentives do not seem very effective to reduce car use.

\section{Transportation networks design}

Prof. Dr. Francesc Robusté,

Technical University Of Catalonia-Barcelonatech

Correo-e: f.robuste@upc.edu

After reviewing the concept and axioms of distance $\mathrm{L}_{\mathrm{k}}\left(\mathrm{L}_{1}=\right.$ grid metric, $\mathrm{L}_{2}=$ Euclidean metric), we'll briefly see some concepts about 
location (center of gravity, median problem, competition and multicriterio selection) and Voronoi diagrams since we'll have to locate transportation terminals and stations or stops: we'll learn that a bus station has to be close enough to the center but not on the center. We'll devote some slides to graphs, a schematic representation of networks first formalized by Euler (1736) to solve the "7 bridges of Königsberg path problem". We'll review the concept of isochrones, accessibility, degrees of separation and topology indexes (Kansky's indicators for networks analysis).

Some transportation network models can be formulated as mathematical programming problems and we'll briefly review transportation demand models and cost benefit analysis indicators. At this point, we are ready to formulate the objective function (minimization of total costs for the users, the operator and externalities) and constraints to define a transportation network "optimal" in some sense.

Several applications deal with "tramway" vs express services, feasibility thresholds for a new high speed rail line, layout of hub airports, bus stations in Barcelona and Donosti, design of the new orthogonal bus network of Barcelona (implemented) and the new radial bus network of Lleida (implemented), and design of the L9 metro line in Barcelona (under construction).

\title{
Value of travel time and public transport
}

\author{
Dr. Ing. Lissy La Paix Puello, \\ University of TwENTE, THE NetherlandS \\ Correo-e: 1.c.lapaixpuello@utwente.nl
}

Travel time and activity time, have been treated as separate notions, albeit with some assumed interdependencies. But, literature show that people accept noticeable higher travel time ratios when travelling by public transport compared with travelling by car. The cost of travel time is reduced as travel time is converted as activity time (towards 
the productive use). Furthermore, the impact of a high quality journey is an important issue in lifestyle and distribution of activities. The productivity of work done while traveling, relative to at work places; and the proportion of travel time saved, which can be used for leisure might have positive effects on the quality of life. Therefore, the opportunity to use travel time productively can be expected to impact the value of time.

In recent years some significant ICT-related innovations have been introduced to large shares of society, but research on the current relation between characteristics of ICT-use and its impact on mobility is limited. Activity fragmentation means to split one activity into several smaller pieces. The society 'on the move', experiences high fragmentation of activities, for example while commuting, or business trips or working from home. ICT enables the activities' fragmentation, for example, phone calls while traveling, etc. Therefore, fragmentation is directly linked to multiactivity, the higher multiactivity the larger fragmentation. Also, there is a "private" strategy in fragmentation of activities which influences car as mode choice. High activity fragmentation implies different valuations of travel time (VTT) and Value of Comfort (VOC).

A stated choice experiment was conducted with over 1,500 respondents in the Rotterdam-The Hague metropolitan area in the Netherlands. The experiment included cost and time factors as well as factors describing the quality of pedestrian and cyclist infrastructure. A set of mixed logit and multilevel hierarchical mixed logit models was estimated for access and egress mode choice to train stations. A first important finding of this study is that the value of travel time estimates for all access and egress modes substantially varies with in-train travel time and journey type. Travel costs of access by BTM increase as the in-train time increases, up to 60 minutes of in-train time. A second conclusion is that the characteristics of egress journeys are of less importance to train users than those of access journeys; the value 
of travel time for bicycle users is $20 \%$ lower for egress journeys, the demand for egress transport modes varies less with bicycle-related cost, and quality attributes of pedestrian egress routes are insignificant. Thirdly, this study confirms the significant role of bicycle parking costs in the selection of the bicycle as access mode.

\section{Traffic Safety and the role of infrastructure management:}

Dr. Thais Rangel, Technical University Of Madrid Correo-e: thais.rangel@upm.es

One of the principles of PPP contracts is to pay the contractor according to the service provided. To that end, a set of performance-based indicators is defined in these contracts in such a way that a better fulfilment of these indicators would entitle the contractor to receive a higher payment. These performance-based indicators intend to reflect the quality of service to the user by measuring lane availability, state of the pavement and signalling, road safety, etc. The presentation focus on road safety indicators. We analyze two aspects: (1) how the road safety incentives are defined and (2) how the road safety indicators are designed in the contracts.

The road safety incentives refers to any kind of economic profit with which the concessionaire will be rewarded according to the contract if its performance is good enough. The main reason behind introducing incentives in toll concession contracts is to encourage the contractors to provide a better service by aligning the social and the private benefits in order to produce a more efficient outcome to society.

The road safety indicators are defined in such a way that if the contractor performs below a certain quality threshold, the contractor will be penalized while if the contractor does it above a certain quality threshold, it will be rewarded. The design of the road safety indicators is quite heterogeneous. We analyze all safety indicators in 
PPP contrats. There are differences both in the variable adopted to measure the outcome and in the final formula employed. Most of the contracts include number of injuries, number of fatalities or a combination of number of light accidents serious accidents and fatal accidents to build the indicator. Besides it is a generalized practice to include exposure to risk expressed by traffic (risk expressed by traffic on the road). Finally, the presentation include some reflections about the effectiveness of the road safety incentives in PPPs.

\section{Accessibility, equity and inclusion in society}

Dr. ING. John Pritchard. ReSEARChER, University Of Twente, The Netherlands

Correo-e: j.p.pritchard@utwente.nl

One of the overarching aims of transport policies should be to improve accessibility. Accessibility is a key concept that has become central to physical planning and in spatial modelling for more than fifty years. Many different accessibility indicators have been developed, typically focused on one or more of the four components of accessibility (i) the land-use component (reflecting the amount, quality and spatial distribution of opportunities), (ii) the transportation component (describing the disutility of travel in terms of time, cost and effort) (iii) the temporal component (reflecting the temporal constraints and variability), and (iv) the individual component (reflecting the needs and abilities of individuals). The growing abundance of detailed spatial data and real-time transport datasets provides many opportunities for improved accessibility modelling, in particular in terms of the temporal and individual components of accessibility, which have often been overlooked in the measures due to data constraints.

The most commonly used accessibility models are static measures of access, since the score for a particular location does not vary temporally. As a result these models may not suitably represent the actual levels of access for different population groups and activity purposes. 
In this presentation we will present our case for relying on accessibility instead of mobility and value of time measurements in order to have a better hope of achieving more equitable outcomes as the result of transport policies. In addition to this, dynamic accessibility measures will be presented that allow us to explore the impact of time on accessibility at different points of the day and reveal how this can lead to unequitable outcomes for certain population groups, that would be otherwise hidden in static accessibility measures.

\section{Conclusions}

This summary presented five key points of smart cities that enhance the value of time of the population. Transport research should be oriented to more multidisciplinary and accurate methods. For example, by integrating the user's needs (equity) with standardized measures of data collection (e.g. GPS data) transport policy measures can be based on more accurate demand estimations. At the same time, those estimations should consider infrastructure related needs, such as traffic safety and network design. 